\title{
STANDAR FISIK IDEAL DALAM PERSPEKTIF BUDAYA DAN KESEHATAN (Kasus: Obesitas Pada Etnis Bugis)
}

\author{
Hikmawati Mas'ud' \\ 1Jurusan Gizi Politeknik kesehatan Makassar
}

\begin{abstract}
Ideal Physical Standard be dream each people, but that is be problematic both the culture and the health perspective. The conception need a study by comprehensive in order to overcome a dichotomy given availabel. This research aim to confirm any view of the culture and health perspective about Ideal Physical Standard. A qualitative descriptive by Grand Theory used an approach of this research. Any data collected by observation, interviews and documentation. A qualitative used to analyze data. The result of this research indicated that An Ideal Physical Standard view of the culture perspective are body compact and full content, better face and confirmity to look in it, face like baby face, give a happy in feeling to touch her/him, and bigger and good in growth. For the health perspective, Ideal Physical Standard oriented to Body Mass Indeks (BMI) <27.0, male abdominal circumference $<90 \mathrm{~cm}$ and women $<80 \mathrm{~cm}$. There are different at using a parameter both them. The health using a quantitative to determining a Ideal Physical Standard, but the Culture using a qualitative, so be gap them.Therefore, they need synergy and integrated them in order to general standard which expected can be received them.
\end{abstract}

Keyword : Ideal Physical Standard, BMI, abdominal circumference, health, culture

\section{PENDAHULUAN}

Konsepsi tentang standar fisik ideal (SFI) pada dasarnya bukanlah hal yang baru dalam sejarah peradaban manusia. Sebelum lahirnya medikalisasi modern atau sistem medis modern, berbagai etnis di dunia sudah memiliki parameter-parameter kualitatif dalam menentukan ukuran standar fisik ideal dalam sistem sosial budayanya. Setelah berkembangnya sistem kesehatan modern, terjadi pergeseran atau transformasi nilai terhadap ukuranukuran standar fisik ideal. Hal ini telah mempengaruhi konsepsi dan paradigma yang mendorong banyak etnis melakukan revitalisasi parameter standar fisik ideal tersebut walaupun masih tetap mempertahankan nilai-nilai budayanya. Namun demikian, tidak sedikit etnis tetap mempertahankan konsepsi standar fisik ideal berdasarkan cara pandangan sistem sosial budayanya.

$$
\text { Purwaningrum N.F (2007) }
$$

bahwa pada setiap kebudayaan terdapat standar ideal daya tarik fisik, dan standar ini akan mempengaruhi citra tubuh seseorang dalam berkembangnya nilai sosial orang tersebut. Kecenderungan yang terjadi dewasa ini adalah adanya dikotomi ataupun perbedaan cara pandang antara perspektif kesehatan dengan perspektif budaya terhadap standar fisik ideal. Perspektif kesehatan cenderung menggunakan parameter kuantitatif dalam menentukan standar fisik ideal seseorang atau masyarakat, sebaliknya, perspektif budaya menggunakan parameter kualitatif dalam menentukan standar fisik ideal. Perbedaan cara pengukuran tersebut menimbulkan pertentantangan atau konflik yang berimplikasi pada timbulnya perbedaan persepsi di kalangan masyarakat mengenai bentuk fisik maupun non fisik tubuh yang diinginkan.

Nilai-nilai budaya mengenai standar fisik ideal cenderung ditolak oleh komunitas medis atau kesehatan tanpa ada usaha untuk melakukan internalisasi nilai-nilai tersebut ke dalam prinsip-prinsip kesehatan. Sebaliknya, prinsip-prinsip kesehatan mengenai standar fisik ideal belum sepenuhnya dapat diterima atau belumj tersosialisasikan secara maksimal di kalangan etnis, sehingga masingmasing pihak cenderung mempertahankan cara pandangnya masing-masing. Atas dasar itu, maka isu permasalahan utama adalah, standar fisik ideal dalam perspektif kesehatan dan perspektif budaya.

\section{METODE PENELITIAN}

Pendekatan penelitian ini adalah penelitian kualitatif, yaitu penelitian yang bersifat menggambarkan hasil temuan 
di lapangan secara utuh dengan menggunakan dasar-dasar teori yang ada. Penelitian ini mengungkap sejumlah fenomena standar fisik ideal dalam perspektif budaya dan kesehatan.

Subjek penelitian berjumlah 16 obes, jenis data yang digunakan adalah data kualitatif dan data kuantitatif. Data kualitatif, yaitu data hasil observasi mengenai berbagai hal terkait subyek penelitian dan data hasil wawancara dengan subyek penelitian, informan kunci dan informan ahli. Data kuantitatif, yaitu data numerik berupa angka-angka, grafik, seperti ukuran berat badan, tinggi badan dan lingkar perut, frekuensi makan, jumlah jenis dan porsi makanan yang dikonsumsi obes dalam sehari. Sumber data dalam penelitian ini adalah data primer, yaitu data yang diperoleh secara langsung di lapangan, berupa : hasil observasi, interview, pengukuran dan dokumentasi, data sekunder yaitu data yang diperoleh dari sumber yang ada melalui kajian literatur, telaah dokumen dan kebijakan-kebijakan normatif, penelusuran melalui internet, penelusuran data dari Rumah Sakit/Puskesmas atau instansi terkait.

Teknik pengumpulan data yang digunakan adalah Observasi yaitu melalui pengamatan langsung terhadap obyek yang diteliti, pencatatan secara sistematis terhadap gejala-gejala yang diteliti. Adapun yang diamati dalam penelitian ini adalah : perilaku/ pola makan, frekuensi makan, tindakantindakan dalam memilih dan mengonsumsi makanan, aktivitas, interaksi dan komunikasi di lingkungan keluarga, lingkungan pekerjaan dan lingkungan masyarakat. Interview, yaitu melalui wawancara langsung, terstruktur dan mendalam dengan informan kunci, dan narasumber. Wawancara dilakukan dengan menggunakan pedoman wawancara. Pengukuran, yaitu BMI (Berat Badan dan Tinggi Badan) dan pengukuran lingkar perut obes. Dokumentasi, yaitu melalui kajian literatur/ kepustakaan, dan sumber tertulis lainnya yang ada kaitannya dengan kebutuhan data dan informasi dalam penelitian ini.
Analisis data dalam penelitian ini dilakukan secara terus menerus sejak awal sampai akhir penelitian. Dalam analisis data, maka data disusun yakni digolongkan dalam pola, tema atau kategori.

\section{HASIL PENELITIAN DAN PEMBAHASAN}

\section{Hasil Penelitian Karakteristik responden}

Berdasarkan hasil penelitian diperoleh gambaran bahwa, ukuran lingkar perut obes bervariasi yakni antara $103 \mathrm{~cm}$ sampai $127 \mathrm{~cm}$, Indeks Massa Tubuh (IMT) juga bervariasi dari 29.0 sampai 38.0. Riwayat obesitas juga bervariasi yakni 1 tahun hingga 19 tahun.

Umur obes bervariasi mulai dari 30 tahun hingga 60 tahun. Status pekerjaan di kalangan obes beragam seperti ibu rumah tangga, wiraswasta/pedagang, PNS/guru, serta petani, nelayan. Tingkat pendidikan bervariasi mulai dari yang tidak pernah sekolah sampai sarjana. Tingkat pendapatan beragam mulai dari satu juta rupiah hingga puluhan juta rupiah. Jumlah tanggungan keluarga juga bervariasi mulai dari yang belum punya anak hingga yang mempunyai lebih dari lima orang anak.

Di kalangan obes, $87,5 \%$ obes mengonsumsi makanan menu utama rata-rata 2 atau 3 kali sehari, dan diantara mereka juga mengonsumsi makanan ringan atau kue-kue sama seperti non obes pada umumnya. Di kalangan obes, bagian-bagian tubuhnya dipenuhi timbunan lemak dan penggumpalan daging, ukuran lingkar perut membesar, berat badannya bertambah, namun mereka tetap aktif melaksanakan tugas kesehariannya di rumah tangga atau keluarga, menjalankan kegiatan pekerjaannya di kantor, atau melakukan kegiatan berdagang, mereka tetap aktif berinteraksi dengan lingkungan sekitarnya seperti halnya orang non obes. Singkatnya bahwa, mereka tetap melaksanakan peran-peran sosialnya. 
Dikalangan obes, 56,2\% menyatakan tidak pernah sakit ataupun merasakan sakit di bagian tubuhnya dan mereka merasa senang dan bangga, nyaman dalam mengonsumsi makanan. $25 \%$ menyatakan mengalami sakit di bagian persendian dan 18,8\% terkadang merasa kurang sehat atau mengalami sakit ringan seperti demam dan flu.

\section{Pandangan Etnis}

Konsepsi pandangan budaya pada etnis Bugis mengenai standar fisik ideal tercermin dari konseptualisasikan NC (2010) bahwa: "Marinessai to macommoe madeceng pakkalinona, makanja akkinanrenna, macca lakkainna parakai makkunrainna, na tarompokeng atuotuonna." Artinya, orang yang secara lahiriah menampilkan bentuk fisik tubuh yang gemuk pertanda kehidupan dunianya elegan, peruntungan usahanya baik, suami pintar memelihara isteri dan mengelola kehidupan rumah tangganya serta memiliki status sosial baik.

Masyarakat pada etnis Bugis mendambakan tubuh yang padat dan berisi, atau disebut Mallise. Hal ini mengacu kepada statemen berikut:

“Makanja'torita anana'e yakko maliselise na makanjato tappana aja'na madoko". Artinya, anak yang tubuhnya berisi dan padat berpadu dengan rupa yang cantik cukup elok dipandang dibanding anak yang tubuhnya kurus.

"lya pakkaleng makanjae iya mallise'pappada ase', iya rupa makanjae iya pappadae ana'lolo mappakarennu rennue, iya mpekke'makanjae na mpekke manu pede'maloppo pede'makanja kanja". Artinya, tubuh yang bagus adalah yang berisi seperti padi, wajah yang rupawan seperti wajah anak bayi yang enak dipandang dan menggembirakan, pertumbuhan tubuh yang baik seperti tumbuhnya seekor anak ayam yang semakin besar semakin cantik atau gagah (hasil wawancara dengan $\mathrm{MI}$, salah seorang tokoh di Mangkoso Barru).

Pernyataan

tersebut mengindikasikan bahwa tubuh yang ideal menurut pandangan etnis Bugis adalah : padat dan berisi (Mallise), bagus tampan mukanya dan elok dipandang, wajah menyerupai rupa anak bayi, wajah dan tubuh menimbulkan rasa senang dan kegembiraan, bertumbuh dengan besar dan baik, sehat. Ciri tubuh tersebut sekaligus menjadi standar ideal bagi daya tarik fisik dan pencitraan tubuh seseorang di lingkungan sosial masyarakatnya.

\section{Pandangan Kesehatan}

Pandangan kesehatan mengacu kepada parameter ukuran berat badan, tinggi badan dan lingkar perut secara kuantitatif. Peningkatan berat badan pada obes disebabkan oleh meningkatnya timbunan lemak yang berasal dari konsumsi makanan dan minuman berlebih (Abdulrahman O.Musaiger. 2011). Penimbunan lemak hampir merata pada tubuh obes mulai dari wajah, leher, bahu, lengan, persendian, dada, perut, paha, hingga punggung dan kaki. Makanan dan minuman yang dikonsumsi secara berlebihan dan tidak teratur sehingga menambah berat badan dan kemudian menjadikan seseorang menjadi obes. 

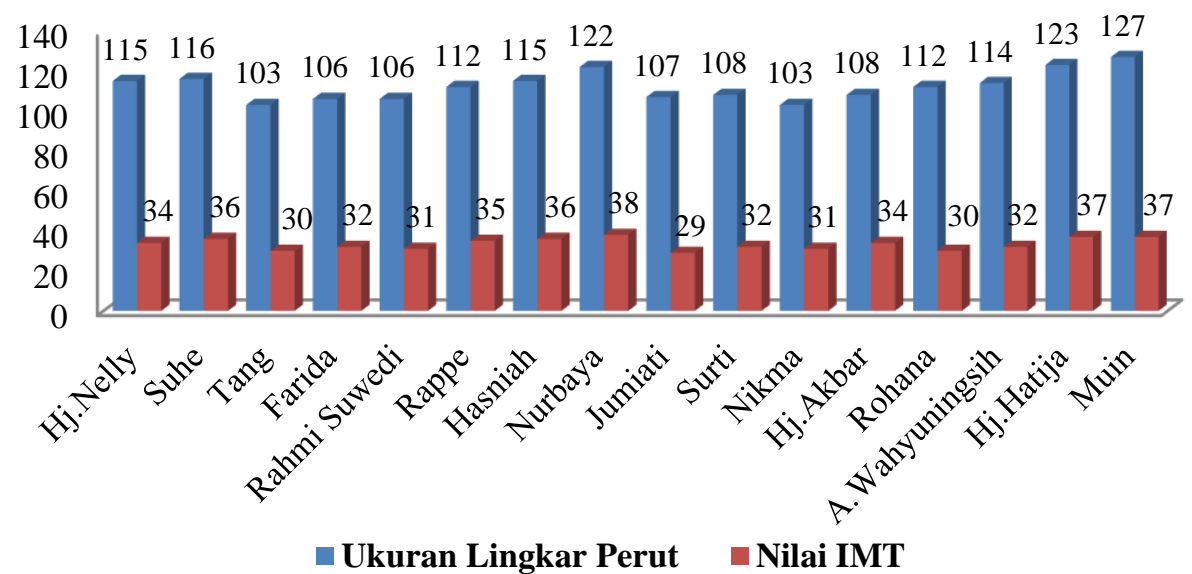

\section{Pembahasan}

Menyimak standar ideal tubuh pada etnis Bugis, dapat dikatakan bahwa obesitas dengan ukuran dan bentuk tubuh dan struktur tubuh alamiah memenuhi kriteria tubuh ideal. Demikian halnya wajah obesitas seperti wajah anak bayi dengan bentuk muka yang bulat dan lebar, wajah terlihat berseri, sehingga memenuhi kriteria citra tubuh ideal. Pencitraan tubuh obesitas mulai dari bagian wajah sampai bagian kaki dengan ukuran dan bentuk tubuh yang besar dan lebar. Pencitraan tubuh tersebut memperlihatkan struktur tubuh alamiah dengan perubahan organ-organ tubuh yang merata. Artinya, ukuran dan bentuk wajah yang besar dan lebar diiringi perubahan ukuran dan bentuk leher, dada, perut, lengan dan tangan, betis dan kaki.

Secara umum dapat dikatakan bahwa pencitraam tubuh terhadap obesitas dalam pandangan kultural etnis Bugis memenuhi standar daya tarik fisik secara kebudayaan, sehingga pendapat yang dikemukakan oleh Purwaningrum N.F (2007) mengenai pengaruh faktor sosiocultural atau standar ideal daya tarik fisik yang berlaku terhadap citra tubuh, adalah benar atau dapat diterima baik. Faktor pengaruh lainnya terhadap citra tubuh adalah reaksi orang lain, perbandingan dengan orang lain, dan identifikasi terhadap orang lain. Hal ini sejalan dengan temuan penelitian bahwa, adanya reaksi orang lain melalui pandangan-pandangan atau anggapananggapan terhadap obesitas cenderung mempengaruhi sikap penerimaan masyarakat terhadap pencitraan tubuh obes (obesitas), sehingga secara sosiokultural posisi obesitas dalam lingkungan etnis tetap dicitrakan tubuhnya dengan baik dan positif, walaupun ada juga mencitrakannya secara negatif dari sisi tertentu, bukan dari sisi kesehatan.

Pandangan positif dan negatif obes mengenai kondisi fisik tubuh sejalan dengan yang dikemukakan oleh Michel Foucault (dalam Pip Jones, 2009:172-181) bahwa citra tubuh merupakan sikap yang dimiliki seseorang terhadap tubuhnya yang dapat berupa penilaian positif dan negatif. Pencitraan tubuh mempengaruhi sikap obes pada satu pihak untuk merubah perilaku makannya. Bermula dari rasa malu menerima teguran baik langsung maupun tidak langsung dari kerabat dekat atau orang lain, kemudian merasa kurang sehat atau sakit, lalu membuatnya berpikir dan mengambil keputusan untuk mengurangi porsi dan intensitas makan bahkan diet. Disisi lain, pencitraan obesitas mempengaruhi obes merasa senang, bahagia, bangga serta meningkatkan perilaku makannya.

Realitas tersebut sejalan pendapat Michel Foucault (dalam Pip Jones, 2009:172-181) bahwa citra tubuh memberikan pengaruh pada perilaku makan, citra tubuh positif akan 
cenderung berperilaku makan yang sehat, sebaliknya citra tubuh negatif akan cenderung berperilaku makan yang kurang sehat. Sosial dan budaya berpengaruh dalam mendefinisikan tubuh dengan karakter alamiah, universal yang tergantung pada waktu dan tempat. Dalam kehidupan sosial dan budaya etnis Bugis, pada dasarnya tubuh berada pada posisi keutamaan dan diagung-agungkan, sehingga nilainilai kepercayaan orang Bugis banyak diasosiasikan dengan usaha-usaha pemeliharaan kesehatan tubuh mulai dari sejak janin hingga usia dewasa dan masa tua.

Asosiasi dan pendefinisian tersebut terutama diwujudkan dalam simbolisasi citra tubuh laki-laki dan perempuan, pencitraan pola hubungan laki-laki dan perempuan baik menjelang pernikahan maupun pada saat menjadi pasangan suami isteri, pola makan dan perilaku makan, standar fisik ideal, pemeliharaan kesehatan tubuh serta simbol-simbol kesejahteraan pada citra tubuh. Kesemuanya diikat oleh nilai-nilai budaya dan norma-norma sosial.

Pandangan etnis Bugis, laki-laki dan perempuan masih cenderung diposisikan secara berbeda. Laki-laki dipandang sebagai orang (tipe manusia) yang bertubuh kuat dan perkasa, otototot kekar, gagah/tampan, dan perilaku tegar dan keras, sedangkan perempuan distereotipkan sebagai tipe manusia yang bertubuh indah, cantik, lemah lembut. Simbolisasi tersebut merupakan produk dari pendefinisian tubuh laki-laki dan perempuan yang kemudian menghasilkan suatu bentuk dan sifat pencitraan tubuh, dan/atau sebaliknya pencitraan tubuh menghasilkan pendefinisian tubuh.

$$
\text { Fenomena }
$$
pendefinisian tersebut juga cenderung berpengaruh pada pencitraan tubuh obesitas laki-laki dan perempuan. Temuan penelitian menunjukkan bahwa jumlah perempuan obesitas lebih banyak dari laki-laki obesitas. Hal ini mengindikasikan bahwa nilai-nilai budaya etnis Bugis tetap menghendaki agar perempuan elok dipandang dengan muka seperti bayi dan menyenangkan. Obesitas pada etnis Bugis dalam pendefinisian tubuh diposisikan sebagai struktur tubuh alamiah sehingga tidak ada pertentangan secara universal. Artinya, obesitas yang berlaku universal juga diakui eksistensinya pada etnis Bugis sebagai produk dari sosial budaya. Pendefinisian tubuh obesitas melahirkan pencitraan tubuh yang juga cenderung berlaku universal, dan karena itu dapat dikatakan bahwa faktor sosial budaya etnis Bugis berperan di dalam pendefinisian dan pencitraan tubuh obesitas.

Budaya etnis Bugis, pola makan dan perilaku makan adalah dua hal yang berbeda. Pola makan lebih merujuk kepada jumlah porsi makanan dan jenis makanan yang disukai dan sering dikonsumsi. Sedangkan perilaku makan lebih merujuk kepada tingkah laku dan hasrat terhadap makanan, intensitas mengonsumsi makanan dalam waktu tertentu, sikap dalam menghadapi dan memperlakukan makanan. Nilai-nilai budaya etnis Bugis menekankan bahwa pola dan perilaku makan yang berlebih adalah kurang baik bagi kesehatan tubuh/jasmaniah, dapat dianggap atau dipersonifikasikan dengan sifat yang buruk seperti rakus, tamak. Demikian halnya dalam norma-norma sosial juga diatur misalnya, berbaring pada saat baru selesai makan akan memiliki perut yang besar, makan di depan pintu dapat menimbulkan teguran dari roh jahat dan sakit, dilarang makan sambil berbicara dianggap tidak baik, mencampuradukkan berbagai jenis makanan ke dalam perut dan memakan sekaligus dianggap rakus dan tubuh dicitrakan negatif.

\section{Sebagaimana}

sudahdikemukakan bahwa standar fisik ideal pada etnis Bugis meliputi: tubuh padat dan berisi (Mallise), wajah menyerupai rupa anak bayi dan elok dipandang serta menimbulkan rasa senang dan kegembiraan, tubuh bertumbuh dengan besar dan baik sehat. Pencitraan tubuh cenderung mempengaruhi standar fisik ideal tersebut, sehingga ada kecenderungan lingkungan sosial budaya etnis Bugis untuk mengagung-agungkan tubuh 
obesitas. Adanya pengaruh pencitraan tersebut menyebabkan obesitas dapat diterima dengan baik sebagai bagian dari produk sosial budaya.

Pencitraan tubuh melalui pemeliharaan kesehatan tubuh pada etnis Bugis tersebut juga tercermin pada nilai-nilai budaya mengenai budaya bersih dan sehat, menghindarkan tubuh dari penyakit melalui berbagai anjuran dan larangan dalam melakukan suatu tindakan/ perbuatan seperti yang sudah dikemukakan sebelumnya. Umumnya obes dengan beragam profesi/pekerjaan atau status sosial ekonomi memperlihatkan kondisi fisik tubuh yang bersih, terawat, elok dipandang, muka berseri-seri. Hal ini juga mengindikasikan bahwa obes melakukan perawatan terhadap tubuhnya dengan baik sehingga citra tubuhnya juga baik.

Pencitraan tubuh obes pada etnis Bugis melalui kesejahteraan tercermin dari rasa senang dan bahagia, kegembiraan serta bangga terhadap tubuhnya, yang memancarkan aura kepada orang lain untuk memandangnya. Obesitas memiliki keunikan dan daya tarik tertentu yang mengundang atau menarik perhatian orang lain. Pencitraan obesitas melalui kesejahteraan juga tercermin dari adanya pandangan elemen warga masyarakat yang mengasosiasikan kemampuan obes dengan pemenuhan kebutuhan ekonominya, mengasosiasikan obesitas dengan kondisi kesejahteraan hidup obes.

$$
\text { Pandangan kesehatan }
$$

memaksakan penyeragaman universal mengenai tubuh yang sehat namun seolah melupakan unsur-unsur esensial dari nilai-nilai kebudayaan dan normanorma sosial yang membentuk pencitraan tubuh sehat. Akibatnya, obesitas yang dalam kesehatan dipandang sebagai penyakit, namun dalam pandangan etnis (khususnya etnis Bugis) tidak demikian, malahan obesitas dicitrakan sebagai pemenuhan standar fisik ideal, hal ini melahirkan kesenjangan dalam pendefinisian pencitraan tubuh.

Temuan penelitian menunjukkan bahwa umumnya obes memandang kondisi tubuh dan kesehatannya baik, merasa senang, bahagia dan bangga. Namun demikian, juga ada obes yang cenderung membuat konsep diri negatif terhadap dirinya setelah merasa sakit, dan seolah ingin menyalahkan obesitas sebagai penyebab sakitnya. Fenomena lainnya bahwa, pandangan orang lain terhadap obesitas juga adakalanya mempengaruhi sikap obes dalam mempertahankan ataupun menggoyahkan konsep dirinya, sehingga pencitraan tubuh juga dipengaruhi dan mempengaruhi konsep diri obes. Pandangan obes yang negatif terhadap obesitasnya juga dipengaruhi oleh konsep diri yang negatif, sebaliknya obes yang memandang positif tubuhnya disebabkan karena konsep dirinya juga positif.

Menyimak lebih jauh, pencitraan tubuh obesitas khususnya pada etnis Bugis pada dasarnya sulit dilepaskan dari proses persepsi, seperti yang dikemukakan oleh Coleman (2003), yakni tahap penerimaan stimulus, tahap pengolahan stimulus dan tahap perubahan stimulus. Hal tersebut juga mengindikasikan bahwa pencitraan tubuh obesitas berdasarkan persepsinya terkait langsung ataupun tidak langsung dengan faktor internal (yang berasal dari dalam dirinya) dan faktor eksternal (yang berasal dari luar/ linkungan sekitarnya). Faktor internal pencitraan tubuh obesitas berdasarkan persepsinya seperti kemauan/ keinginan atau motivasi-motivasi dari dalam diri obes untuk memiliki tubuh obesitas, hasrat dan kebiasaan makan. Sedangkan faktor eksternal seperti stimulus itu sendiri, baik sosial maupun fisik.

Pengaruh pencitraan terhadap persepsi obesitas pada akhirnya juga mempengaruhi cara berpikir obes, bekerja, serta bersikap pada dirinya. Hal ini sangat ditentukan oleh kemampuan obes mengolah informasi baik stimulus informasi baik stimulus fisik maupun stimulus sosial, kemampuan menyesuaikan diri atau sikap beradaptasi dengan lingkungan sekitarnya, kemampuan dalam mempengaruhi pandangan atau cara 
berpikir orang lain terhadap dirinya serta kemampuan berperilaku sesuai nilainilai budaya dan norma-norma sosialnya. Pencitraan tubuh obesitas dipengaruhi oleh faktor sosiokultur, interaksi sosial, konsep diri dan persepsi. Pencitraan tubuh bukan sekedar dipengaruhi tetapi juga mempengaruhi sosial budaya, perilaku kesehatan, motivasi obesitas, pola makan/ budaya makan, perilaku makan, konsep diri dan persepsi obes.

\section{Transformasi Nilai}

Setiap etnis secara universal, termasuk etnis Bugis di Kabupaten Barru, pada dasarnya sulit melepaskan diri dari dinamika perkembangan terutama sosial, budaya dan ekonomi. Dinamika perkembangan sosial dapat menimbulkan perubahan-perubahan di bidang tatanan dan norma-norma sosial, interaksi, pendidikan, pekerjaan/ profesi dan lainnya. Dinamika perkembangan budaya dapat menimbulkan perubahanperubahan dalam aspek nilai, kepercayaan, tradisi, percampuran atau akulturasi budaya. Dinamika perkembangan ekonomi dapat menimbulkan perubahan-perubahan dalam hal sistem ekonomi, gaya hidup, perilaku konsumtif, pendapatan.

$$
\text { Dinamika perkembangan }
$$

sosial, budaya dan ekonomi tersebut terjadi seiring dengan dimensi waktu, yang berimplikasi luas pada pandangan etnis terhadap pengetahuan, pengalaman, motivasi, budaya makan (nilai-nilai kepercayaan, perilaku makan atau atau pola makan) dan pencitraan terhadap obesitas. Pandangan etnis terhadap obesitas yang mencakup aspek sosial budaya dan ekonomi, tercermin dari pengetahuan, pengalaman, motivasi, budaya makan dan pencitraan. Pandangan tersebut mengalami perubahan atau transformasi nilai seiring perkembangan waktu (dimensi waktu), yang dimulai dari konsep yang dikemukakan oleh NC kemudian kepada IT, hingga kepada Saya yang mengajukan konsep baru dan sebagai dasar bagi konsep ke depan.

$$
\text { Pandangan etnis Bugis }
$$

terhadap obesitas yang dikonseptualisasikan oleh NC (2010) menyatakan bahwa: "Marinessai to macommoe madeceng pakkalinona, makanja akkinanrenna, macca lakkainna parakai makkunrainna, na tarompokeng atuotuonna." Artinya, orang yang secara lahiriah menampilkan bentuk fisik tubuh yang gemuk pertanda kehidupan dunianya elegan, peruntungan usahanya baik, suami pintar memelihara isteri dan mengelola kehidupan rumah tangganya serta memiliki status sosial baik.

Konsepsi ini mencerminkan suatu parameter bagi postur tubuh yang dikehendaki di kalangan etnis Bugis dengan mengambil perumpamaan yaitu: tubuh yang baik laksana padi yang berisi, rupa yang baik menyerupai muka anak bayi, yang menyenangkan dan menggembirakan, perubahan bentuk tubuh yang baik adalah yang menyerupai tumbuh kembangnya ayam yang semakin besar semakin bagus. Konsepsi tersebut pada dasarnya sudah menunjukkan indikasi pergeseran sebab, ada obes yang meskipun tubuhnya gemuk namun kegemukannya lebih disebabkan oleh kandungan lemak atau daging yang tebal membungkus tulang, yang lembek, tidak sekeras padi yang berisi. Demikian halnya, orang gemuk yang semakin gemuk bukan lagi enak dipandang melainkan semakin kurang menarik atau tidak elok dipandang. Satu hal yang masih tetap relevan adalah muka / pipi para obes menyerupai muka atau rupa anak bayi, yang banyak orang tertarik dan merasa senang melihatnya.

Secara keseluruhan dari konsep pandangan etnis Bugis yang dikemukakan oleh IT tersebut, sebagian masih relevan namun kecenderungannya lebih banyak mengalami pergeseran nilai. Atas dasar itu, maka saya mengajukan suatu konsep pandangan etnis bahwa: Sikessing-kessingna to macommoe iyanatu ia maccae parakai alena, najaga iyarega toli napparessa kesehatannna, mallise i pakkaleangna pappada ase, madeceng pakkalinona, makanja akkinanrenna, tarompokeng atuotuonna, 
makanjae tappana pappada ana'lolo mappakarennu rennue. Artinya, sebaikbaiknya orang gemuk adalah yang pandai memelihara dan mengontrol kesehatannya, tubuhnya berisi dan padat laksana padi, kehidupan dunianya elegan, peruntungan usahanya baik, status sosial ekonomi baik, tampannya bagus-bersih dan menyenangkan.

Kesehatan menempati tempat atau prioritas yang tertinggi, kemudian perilaku dalam memelihara kesehatan yang baik dan sehat, perilaku kesehatan yang diinginkan, kemudian menghasilkan tubuh yang padat dan berisi serta sehat, kehidupan dan penghidupannya bagus, usahanya maju, status social ekonominya baik yang dapat menyebabkan ia terpandang dan dapat menjadi contoh yang baik bagi sekitarnya, badan dan muka bersih, menarik dan menyenangkan dipandang.

\section{KESIMPULAN DAN SARAN}

Standar fisik ideal dalam pandangan budaya adalah padat dan berisi, bagus tampan mukanya dan elok dipandang, wajah menyerupai rupa anak bayi, wajah dan tubuh menimbulkan rasa senang dan kegembiraan, dan bertumbuh dengan besar dan baik, sehat. Dalam pandangan kesehatan, standar fisik ideal adalah dengan IMT $<27.0$. Ada perbedaan penggunaan ukuran, yaitu perspektif budaya menggunakan pendekatan kualitatif, sedangkan perspektif kesehatan menggunakan pendekatan kuantitatif, sehingga terjadi perbedaan atau kesenjangan diantara keduanya. Oleh karena itu, perlu ada integrasi keduanya untuk menetapkan standar fisik ideal yang berlaku secara umum yang dapat diterima oleh perspektif budaya dan perspektif kesehatan.

\section{DAFTAR PUSTAKA}

Almatsier, S. 2009. Prinsip Dasar IImu Gizi. Jakarta: Dramedia Pustaka Utama.

Abdulrahman O.Musaiger.2011. Overweight and Obesity in EasternMediterranean
Region:Prevalence and

Possible Causes. Journal of Obesity Volume 2011, Article ID 407237, 17 pages

Alexandra A. Brewis, et al. 2011. Body Norms and Fat Stigma inGlobal Perspective. Chicago Journal, Source: Current Anthropology, Vol. 52, No. 2 (April 2011), pp. 269-276

Bagong, Suyanto. 2010. Sosiologi Teks Pengantar dan Terapan. Jakarta: Kencana Prenada Media Group.

Barker, Chris. 2004 Cultures Study, Teori dan Praktik. Yogyakarta: Kreasi Kencana Brookfield USA: Avebury.

Bungin, Burhan. 2010. Penelitian Kualitatif. Jakarta: Kencana Prenada MediaGroup, Cetakan IV.

Caroline Davis,et.al. 2011. Evidence that 'food addiction' is a valid phenotype of obesity.Journal Appetite Elsevier Canada.

Emy Huriyati. 2006. Prevalensi Obesitas Siswa Siswi SLTP Kota Yogyakarta. Jurnal Gizi Klinik Indonesia, 3 (1). 1-5

Fein, O. 1995. The Influence of Social Class and Health Status : American and British Researh on Health Inequalit. Journal Internal Medicine. Terjemahan. St.Louis, Mosby.

Hadi, Hamam. 2005. Beban Ganda Masalah Gizi Dan Implikasinya Terhadap Kebijakan Pembangunan Kesehatan Nasional. Pidato Pengukuhan Jabatan Guru Besar pada Fakultas KedokteranUniversitas Gadjah Mada.

Hamid, Abu. 2006. Kebudayaan Bugis. Makassar: Dinas Kebudayaan dan Parwisata Provinsi Sulawesi Selatan.

Jufri. 2007. Struktur Makro dalam Wacana Lontara La Galigo Suatu Kajian Wacana Kritis. Jurnal Penelitian Kependidikan. Jakarta 17 (2) Des.

Miles B. Nfattewa, Huberman Michael, A., 1984. Qualitative Data 
Analysis. New Delhi: SAGE Fublication India.

NC dan IT. 2010. Wawancara Observasi Awal Penelitian di Mangkoso Kabupaten Barru Sulawesi Selatan.

Nazsir, Nasrullah. 2008. Teori-Teori Sosiologi. Bandung: Widya Padjadjaran.

Nicholas A. Christaki and James $\mathrm{H}$.

Fowler. 2011. The Spread of Obesity in

a Large Social Network Over 32Years.

The new england journal of medicine.

Pelras, C. 2005a. Budaya Bugis Sebuah

Tradisi Modernitas. Tapak-

Tapak Waktu. Makassar: Penerbit Ininnawa.

2005b. The Bugis.Terjemahan

Abdul Rahman Abu Manusia

Bugis. Jakarta: Nalar

Bekerjasama dengan Forum Jakarta-Paris.

Pip, Jones. 2009. Pengantar TeoriTeori Sosial. Jakarta: Yayasan Obor Indonesia.

Purwaningrum N.F. 2007. Hubungan Antara Citra Raga Dengan
Perilaku Makan Pada Remaja Putri. Skripsi tidak diterbitkan. Surakarta: Fakultas Psikologi Universitas Muhammadiyah .

Riskesdas. 2007. Laporan Hasil Riset Kesehatan Dasar Nasional. Jakarta: Depkes RI.

Ritenbaugh, C, 1991. Body Size And Shape: A Dialogue Of Culture And Biology. Medical Antropology Journal, 13. 173180.

Sonny C, Nurmiati A, Ika W. 2007. Hubungan Antara Obesitas Dengan Psikopatologi Pada Siswa SMU di Jakarta. Jurnal Cermin Dunia Kedokteran Jakarta 34 (6/159). 289

Sudarma. Momon, 2008. Sosiologi Kesehatan. Jakarta: Penerbit Salemba Medika

Irmayanti M, Budianto. 2004. Dimensi Etis terhadap Budaya Makan dan Dampaknya pada Masyarakat. Jurnal Makara Sosial Humaniora Jakarta. 